\title{
AGGREGATE ANGULARITY EFEFCTS ON MECHANICAL PROPERTIES OF ASPHALT CONCRETE
}

\author{
Lee P. Leon \\ Faculty of Engineering, The University of the West Indies, Trinidad \\ Email: leepleon@gmail.com
}

\begin{abstract}
Aggregates have significant influence on the serviceability and performance of flexible pavements. Estimation of the effects of the classifications of aggregate angularity on mechanical properties of asphalt concrete is understudied because of its complexity. This paper identifies the limitations of aggregate angularity and mix performance in existing studies and present experimental results of the influence of coarse aggregate angularity (CAA) on the mechanical behaviour of dense graded asphalt mixtures. Four mixtures of different classes of coarse aggregate angularity (rounded to angular) were compacted to cylindrical heights of 63,100 and $150 \mathrm{~mm}$ each. Geometric characterization of the particle angularity have been evaluated using Aggregate Imaging System (AIMS). Additionally, mechanical and performance tests have been evaluated at three temperatures $\left(25,35\right.$ and $\left.45{ }^{\circ} \mathrm{C}\right)$. Principle results of the study demonstrated that tangential modulus, compressive strength, elastic, viscoelastic and viscoplastic properties are highly influence by changes in coarse aggregate angularity. The resilient stiffness modulus and recovered (elastic) creep strain however, were not significantly influenced by these changes. The influence of a particular angularity classification maybe useful to road engineers when evaluating the performance prediction of asphalt concrete.
\end{abstract}

Keywords: AIMS, Aggregate angularity, Asphalt concrete, Mechanical behaviour, Pavement performance.

https://doi.org/10.47412/WCLJ3100

\section{Introduction}

Pavement performance is largely determined by the characteristics of its constituents: aggregates, asphalt binders, and additives. The occurrence of flexible pavement defects is a function of material properties, loading, environmental conditions, and structural design (e.g., thickness of pavement layers) [3]. Mineral aggregates make up 90-95\% of the mass of asphalt mix. At high temperatures, asphalt mixes behave like granular non-linear elastic materials; therefore, aggregate shape parameters play an important role in providing resistance to pavement defects. Souza et al. [13] suggested that a better and more scientific understanding of the effects of aggregate angularity is necessary, given that the minimum angularity requirements for bituminous mix design significantly affect both mix production costs and long-term pavement performance. Thus, the refinement of aggregate angularity criteria is crucial for state highway agencies and pavement/materials contractors. 
Angularity as defined by geologist [14] is whether aggregate particle edges are sharp or round; while pavement engineers [8] defined it as the difference between a particle radius in a certain direction and that of an equivalent ellipse. The measurement process of angularity is being gradually accepted from the personnel interpretation techniques (ASTM D 3398 and ASTM C 1252) to computerized imaging direct measurement techniques. One of the methods used in this research is known as Aggregate Imaging System (AIMS) which classify fine and coarse aggregates particles as an index which describes the aggregate as being rounded $(<2000)$, sub-rounded $(2000-$ 3000), sub-angular (3000-4500) and angular (>4500).

Data from full-scale rutting tests performed at an accelerated pavement testing (APT) facility indicated the effects of manufactured and natural aggregate on permanent deformation (rutting) [11]. The effect of aggregate angularity on rutting and fatigue performance was investigated by [13] through experimental tests and micro-structure finite-element simulations. One summary concluded that analysis of rutting performance showed the same trend in the static creep test and the Asphalt pavement analyzer test. That is, increased coarse and fine aggregate angularity in a mixture improved the mixture's resistance to rutting. The combination of aggregates properties, mix volumetric properties, test temperature and stress levels have significant effects on the rutting and fatigue failure of asphalt concrete [10], [12].

The effects of coarse aggregate angularity on measured laboratory permanent deformation of hot mix asphalt was investigated by [9] and results indicated that at temperatures close to the binder's upper grade limit, aggregate structures played a critical role in the rut resistance of HMA mixtures. The study used the AIMS to characterize this behaviour and recorded aggregate materials of subrounded description of angularity. The effects of the other three classes of angularity were not investigated. Some studies such as [1], [4], [5] and [9] have evaluated asphalt concrete and using the imaging systems to differentiate the angularity properties. These studies did not have a full spectrum of the particular angularity as discussed previously. This limitation potentially contributes to uncertainties in whether or not the angularity property affected the output data. Recognizing the importance of aggregate morphological properties, it is necessary to consider aggregate shape parameters in the estimation of permanent deformation strains. An important element in the design of the rut-resistant pavements is screening of asphalt mixtures for the rut susceptibility during mix design.

The main objective of this paper is to evaluate the angularity ranges and their effects on laboratory stiffness, uncompressive strength and creep deformation behaviour of asphalt concrete. The Aggregate Imaging System (AIMS) was used to classify aggregates of the mixture into four ranges of coarse aggregate angularity (rounded, sub-rounded, sub-angular and angular). Laboratory performance tests were conducted to show an existing relationship between coarse particle angularity and the permanent deformation behaviour of dense graded asphalt mixes.

\section{Methodology}

\subsection{Materials}

Three types of aggregates (river gravel, limestone, sharp sand) were investigated prior to mix designs. These aggregates were selected since they are readily available and for their angularity and strength properties. The asphalt binder utilized in this research was obtained from Trinidad Lake Asphalt, with a penetration grade of 60/75 according to ASTM D5 / D5M-13, and specific gravity according to ASTM D 70 of 1.02 . This binder type has typically been used for high traffic 
volume roads and airport pavements. The reference dense graded mix blended as presented in Fig. 1 was produced using the gradation of the previously mentioned aggregates.

\subsection{Mix Design}

Four asphalt concrete mixes were investigated. The coarse aggregate in the mixes were measured using the AIMS. The first mix was an asphalt concrete mixture where all the coarse aggregates used were classified as being rounded (RM), followed by mixes of sub-rounded (SRM), subangular (SAM) and angular (SA) respectively. Fig. 2 shows descriptions of the research aggregate particles and its AIMS angularity index. The asphalt concrete mixture was designed according to the Marshall Mix design procedure to obtain the optimum binder content for the aggregate blend.

\subsection{Sample Preparation}

Using the optimum binder content for the each of the four mix types, the mixture of aggregate and binder were compacted using a gyratory compactor. The gyratory compacted was used to control the voids ratio and density of the mixes. The specimens were compacted with three (3) different diameter to height ratios of $65 \mathrm{~mm}(1: 0.5), 100 \mathrm{~mm}(1: 1)$ and $150 \mathrm{~mm}(1: 1.5)$. These heights represent the typical pavement surface thicknesses. The shortest specimen was used in the Indirect Tensile Stiffness Modulus (ITSM) test while the remaining samples were used in the Uniaxial Compression (UC), Static Creep (SCT) and Repeated Load (RLT) tests. A total of 272 cylindrical samples were compacted to a desired average field air voids percent of $7 \%$.

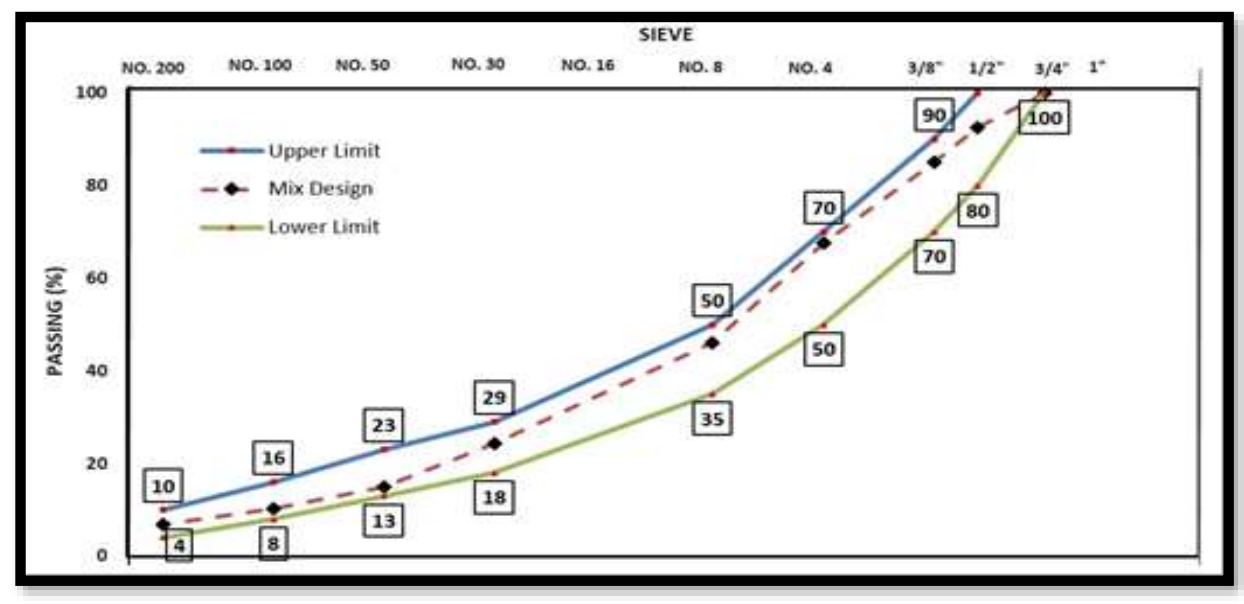

Figure 5: Aggregate gradation of asphalt concrete mixture 


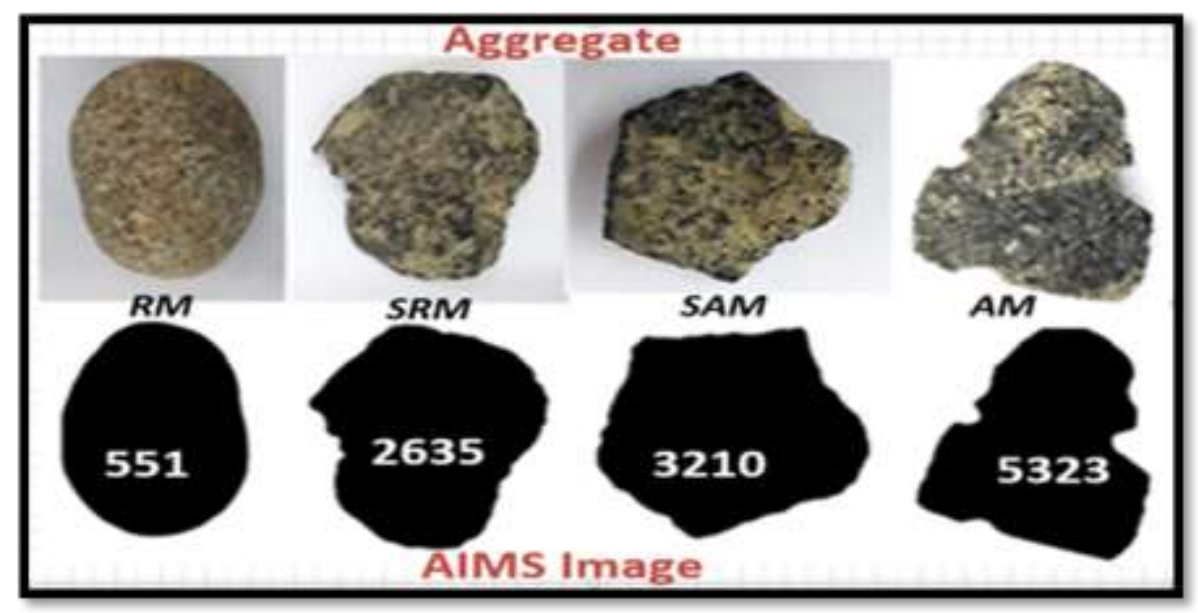

Figure 6: Aggregate particle and AIMS angularity description

\section{Data and Analysis}

\subsection{Indirect Tensile Stiffness Modulus (ITSM)}

The resilient stiffness modulus test was performed to assess the elastic (stiffness) properties of asphalt mixture [2], [6]. The standard test temperature is $25^{\circ} \mathrm{C}$, however, additional temperature of $35^{\circ} \mathrm{C}$ was used to observed the stiffness at a high (hot) temperature. At higher test temperatures, mixtures have seen to exhibit excessive deformation leading to collapse. The trend in Fig. 3 suggests that there is no significant influence of coarse aggregate angularity on the stiffness behaviour of the mixtures. Although there was no significant difference in stiffness modulus trend observed, the conclusions of the stiffness behaviour can be attributed to the theory that supports the binder as having the major influence on the stiffness of an asphaltic mixture. This conclusion indicated that binder source, binder grade and asphalt content would have a significant effect on stiffness modulus.

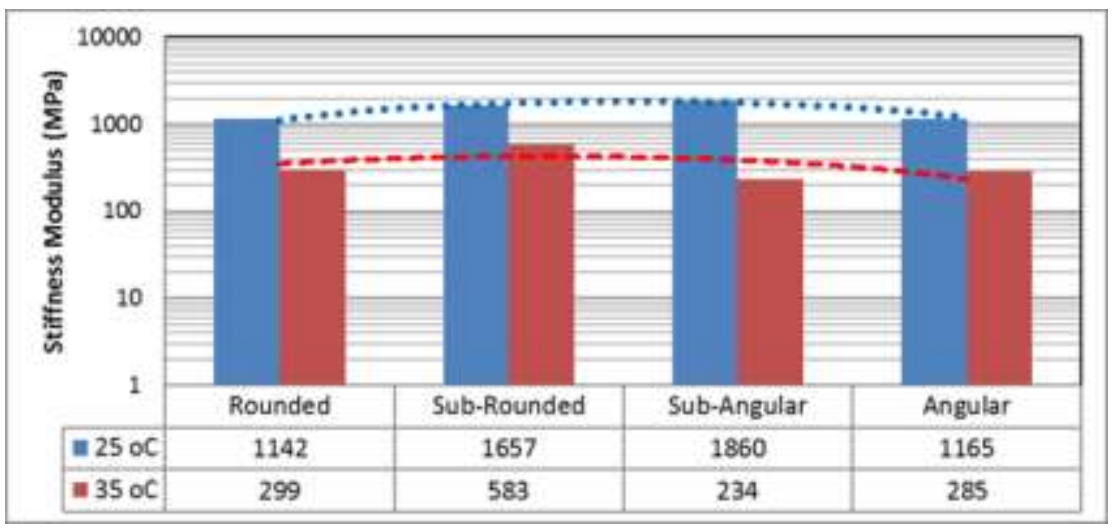

Figure 7: Stiffness Modulus vs Coarse Aggregate Angularity

Typically, pavement designers use the modulus of elasticity input for asphalt concrete as an approximate average value of $3000 \mathrm{MPa}(435 \mathrm{ksi})$ at $4 \%$ air voids. Trinidad and Tobago mixes produced have recorded low average values within the range of $1500-2200 \mathrm{MPa}$ for test 
temperature of $25^{\circ} \mathrm{C}$ and $4 \%$ air voids. Therefore, the low value can indicate the possible deficiency in the pavement layer design (thickness) when the correct mix stiffness values are not incorporated.

\subsection{Uniaxial Compression Test (UCT)}

The specimens were tested under static uniaxial compression at a continuous loading rate of 24 $\mathrm{mm} / \mathrm{min}$ using an MTS (material testing machine). Compressive stress applied to asphalt concrete causes unbalanced forces in the system from which results in deformation, cracks and fatigue failure. These applications are useful in determining the plastic and elastic limits of asphalt concrete (AC). Plastic deformation and fatigue failure occur when the yield point of the material has been exceeded and this is a problem seen in many AC pavements today, hence, a connection between the stress and strain in AC needs to be explored especially for the purpose of designing.

By visual analysis, cylindrical specimens with height $100 \mathrm{~mm}$ exhibited bulging failure, whereas the specimens $150 \mathrm{~mm}$ exhibited shear failure. The failure modes of specimens are illustrated in Fig. 4. The Mohr-Coulomb theory is a law linearly relating the shear to the normal stress. The Mohr Coulomb Circle was used to validate this failure angle to be associated with the mode of failure as being true shear failure. The average failure (shear) angles $(\Theta)$ for all mix types were measured to be an average of $64^{\circ}$. The friction angles $\beta$ was calculated to be an averaged value of $32^{\circ}$. The laboratory results give representative behaviour for an asphalt concrete layer in insitu compression.

An asphalt concrete specimen under compression behaves as an elasto-plastic material. This behaviour is due to the material properties such as viscoelasticity and plasticity of the binder and the aggregates respectively. The general shape of the resulting stress-strain graphs in Fig. 5, shows that irrespective of mix type, sample specimens which were $150 \mathrm{~mm}$ failed at a lower stress level than the $100 \mathrm{~mm}$ samples. This early onset of failure occurred due to the diameter-height ratio. As particle angularity and sample height increases so does the elastic modulus increases. Failure stress decreases with an increase in sample height while strain at failure decreased. However, this does not affect the modes of failure between the two different sample heights.
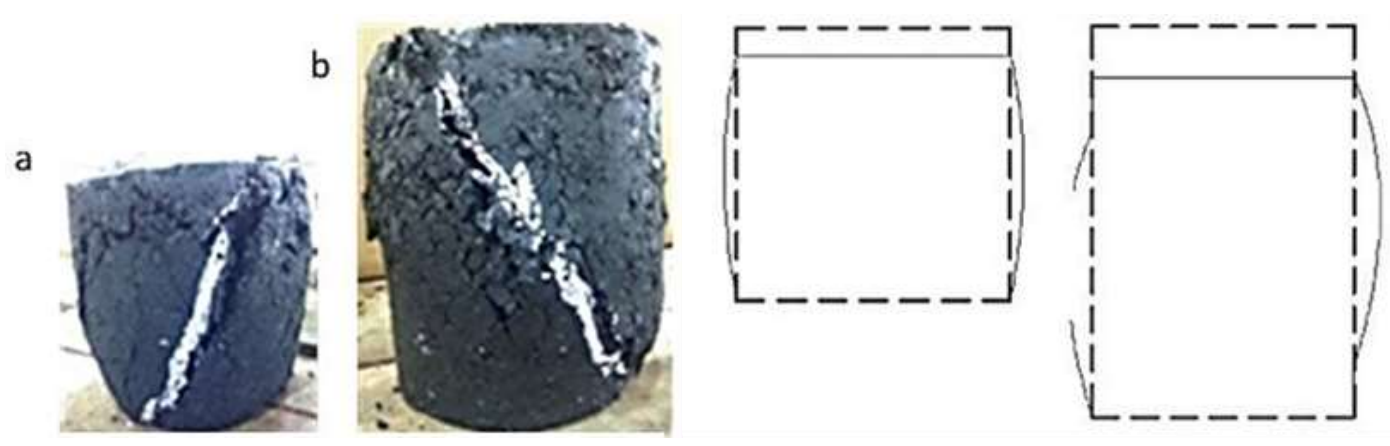

Figure 8: Failed test samples (a) $100 \mathrm{~mm}$ height (b) $150 \mathrm{~mm}$ height 


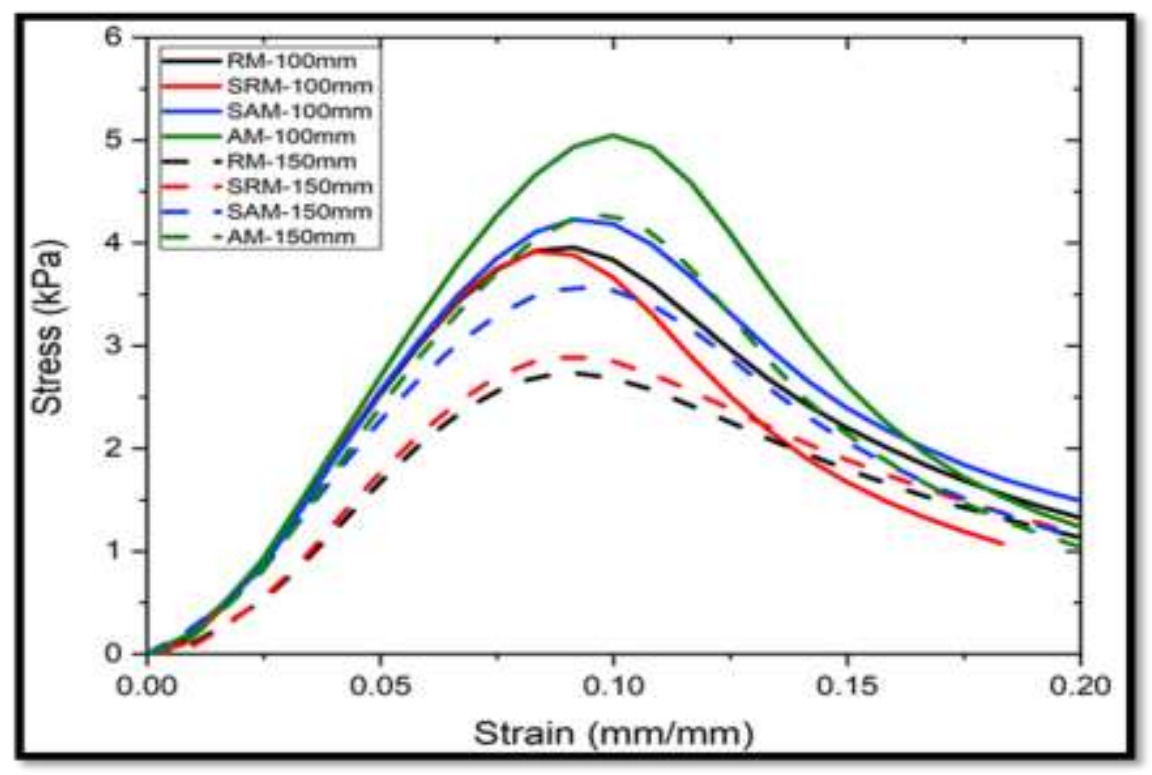

Figure 9: Stress-strain curve

Compressive strength of asphalt concrete arises from the resistance of the aggregate, resulting from the aggregate interlocking and the stiffness of the asphalt cement. Specimens $100 \mathrm{~mm}$ in height attained higher compressive strength than specimens $150 \mathrm{~mm}$ in height for any mix types (Fig. 6a). Failure stress decreases with an increase in sample height and coarse angularity index. This behaviour suggest that as the aggregate angularity increases so does the stiffness and aggregate interlocking properties of the mixture. Smaller samples can endure more stress than taller sample without confining stresses. There is a significant statistical relationship between angularity and ultimate compressive strength of samples as presented by both the coefficient of determination $\left(\mathrm{R}^{2}\right)$ and Pearson's correlation (r) for $100 \mathrm{~mm}$ and $150 \mathrm{~mm}$ samples are $0.683,0.840$ and 0.825 , 0.916 respectively.

The elastic properties of the bitumen contribute greatly to that of the sample as a whole. As particle angularity and sample height increase so does the elastic modulus as displayed in Fig. 6b. There is a significant statistical relationship between angularity and tangent modulus. 

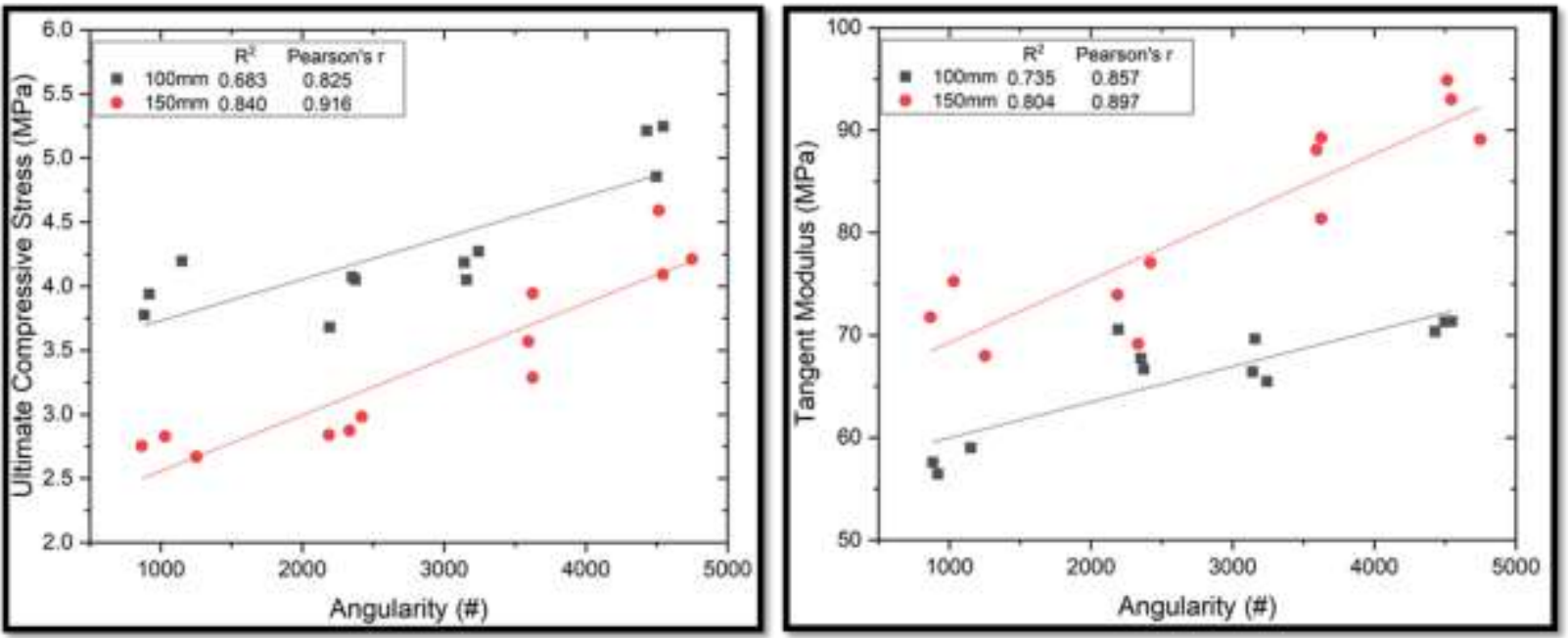

Figure 10: Angularity vs (a) compressive strength (b) elastic (tangential) modulus of mixes

\subsection{Uniaxial Static Creep Test (SCT)}

The uniaxial SCT was conducted to measure the resistance of asphalt concrete to flow. When the indirect SCT was performed, creep data were obtained in the loading and relaxation stages as represented in Fig. 7. The rounded mixes had the highest deformation strain over loading time. The largest permanent strains were observed in $150 \mathrm{~mm}$ height samples at $200 \mathrm{kPa}$ loading stress, while the smallest strains were observed in $100 \mathrm{~mm}$ height samples at $70 \mathrm{kPa}$ loading stress. At low temperatures of $25^{\circ} \mathrm{C}$, as the loading stress levels increase, so do the total strains to an average value of $28 \%$. The resistance to static creep deformation however is increased as the particle angularity increased. At ambient temperatures, all samples experienced the applied and relaxation stages of the test.
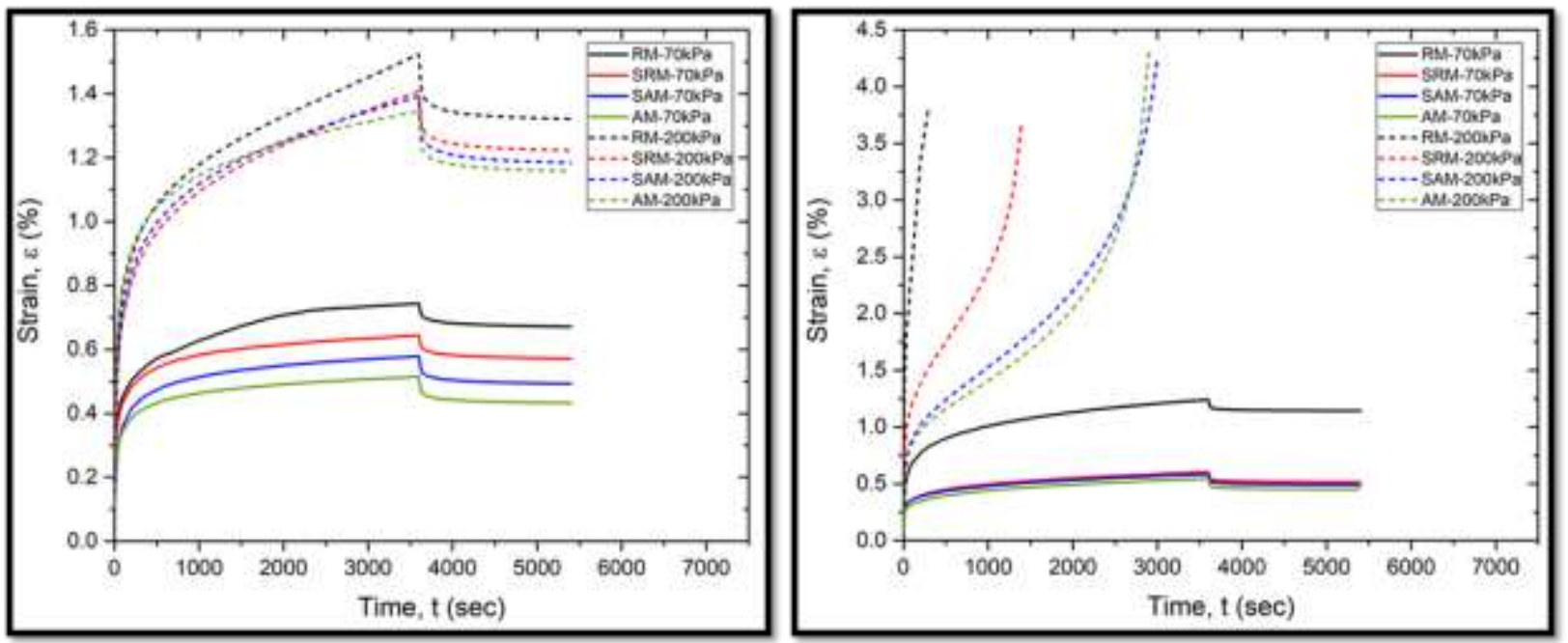

Figure 11: Static creep test at (a) $25^{\circ} \mathrm{C}$ (b) $40^{\circ} \mathrm{C}$ 
When the temperature increased to $40^{\circ} \mathrm{C}$, the $150 \mathrm{~mm}$ height samples failed to reach the relaxation stages, which implies that temperature has a major influence on the behaviour of mixes. As with the ambient temperature-tested samples, an average value of $28 \%$ total strains increase is observed as the loading stress levels increase. This relationship is true for the behaviour of pavements in the field where damage due to heavy vehicles can be exponential.

The statistical analysis presented in Table 1 was done to measure the linear correlation and approximates the relationship between coarse angularity and permanent deformation. The negative Pearson's correlation for permanent strain indicates that as aggregate angularity increases the plastic strain decreases which suggests that increase in angularity produces mixes more resistant to deformation. At low temperatures the data shows that aggregate angularity did not have a significant effect on permanent deformation $\left(R^{2}\right.$ varies from $\left.0.070-0.467\right)$. However, at high temperature the coefficient of determination $\left(\mathrm{R}^{2}=0.594\right)$ suggests coarse aggregate particle angularity does have an influences on the resistance of asphalt concrete to deformation. Prediction models of permanent deformation at high temperatures could have an inclusion of the aggregates angularity properties, to significantly evaluate mix behaviour.

Table 6: Statistical analysis of static creep tests.

\begin{tabular}{|c|c|c|c|c|c|}
\hline \multirow[t]{3}{*}{ Statistics } & \multirow{4}{*}{$\begin{array}{c}\text { Creep } \\
\text { Data }\end{array}$} & \multicolumn{4}{|c|}{ Sample Height } \\
\hline & & \multicolumn{2}{|c|}{$100 \mathrm{~mm}$} & \multicolumn{2}{|c|}{$150 \mathrm{~mm}$} \\
\hline & & $70 \mathrm{kPa}$ & $200 \mathrm{kPa}$ & $70 \mathrm{kPa}$ & $200 \mathrm{kPa}$ \\
\hline & & $25^{\circ} \mathrm{C}$ & & & \\
\hline \multirow[t]{2}{*}{ Pearson Corr. (r) } & $\varepsilon_{\mathrm{r}}$ & 0.767 & 0.030 & 0.768 & -0.287 \\
\hline & $\varepsilon_{\mathrm{p}}$ & -0.571 & -0.265 & -0.523 & -0.683 \\
\hline \multirow[t]{2}{*}{$\mathbf{R}^{2}$} & $\varepsilon_{\mathrm{r}}$ & 0.588 & 0.000 & 0.589 & 0.082 \\
\hline & $\varepsilon_{\mathrm{p}}$ & 0.326 & 0.070 & 0.273 & 0.467 \\
\hline \multirow[t]{2}{*}{ ANOVA (Ang. vs $\left.\varepsilon_{p}\right)$} & sig. & $S(0.053)$ & 0.081 & 0.491 & $S(0.014)$ \\
\hline & & $40{ }^{\circ} \mathrm{C}$ & & & \\
\hline \multirow[t]{2}{*}{ Pearson Corr. (r) } & $\varepsilon_{\mathrm{r}}$ & -0.263 & 0.375 & 0.600 & 0.000 \\
\hline & $\varepsilon_{\mathrm{p}}$ & -0.767 & -0.486 & -0.771 & -0.768 \\
\hline \multirow[t]{2}{*}{$\mathbf{R}^{2}$} & $\varepsilon_{\mathrm{r}}$ & 0.069 & 0.140 & 0.359 & 0.000 \\
\hline & $\varepsilon_{\mathrm{p}}$ & 0.588 & 0.236 & 0.594 & 0.590 \\
\hline ANOVA (Ang. vs $\varepsilon_{p}$ ) & sig. & $S(0.003)$ & $S(0.006)$ & 0.100 & $S(0.004)$ \\
\hline
\end{tabular}

$\mathrm{S}$, significant at $95 \%$ confidence interval level

Ang. - means coarse aggregate angularity index

For the static creep ANOVA analysis, there were acceptable correlations observed between the coarse aggregate angularity index $(C A I)$ and permanent deformation strains concluding that coarse 
angularity has an influence on the outputs of resistance of mixtures to permanent deformation no matter the stress (loading) levels.

\subsection{Repeated Axial Load Creep Test (RLAT)}

The RLAT test recorded the cumulative permanent deformation and reported it as a function of number of load applications. The RLAT results visualized in Fig. 8 show the general trend of the four mixes under the specified loading, heights and temperature conditions. For the sake of uniformity, the following test conditions were used; constant stress (70 and $200 \mathrm{kPa})$, height (100 and $150 \mathrm{kPa}$ ) and temperature $\left(25\right.$ and $\left.40{ }^{\circ} \mathrm{C}\right)$. The load cycles and strain relationship as shown in Fig. 8 are defined in three zones: primary, secondary, and tertiary. Temperature increases the onset of the tertiary stage of deformation. As shown in Fig. $7 \mathrm{~b}$, at high temperature $\left(40{ }^{\circ} \mathrm{C}\right)$ the permanent strain within the steady state behaviour of deformation happens at an earlier time than in mixes at ambient temperature. This behaviour is the same for any angularity-classified mix since the rise in temperature causes the binder to have less influence on resistance to pavement deformation.
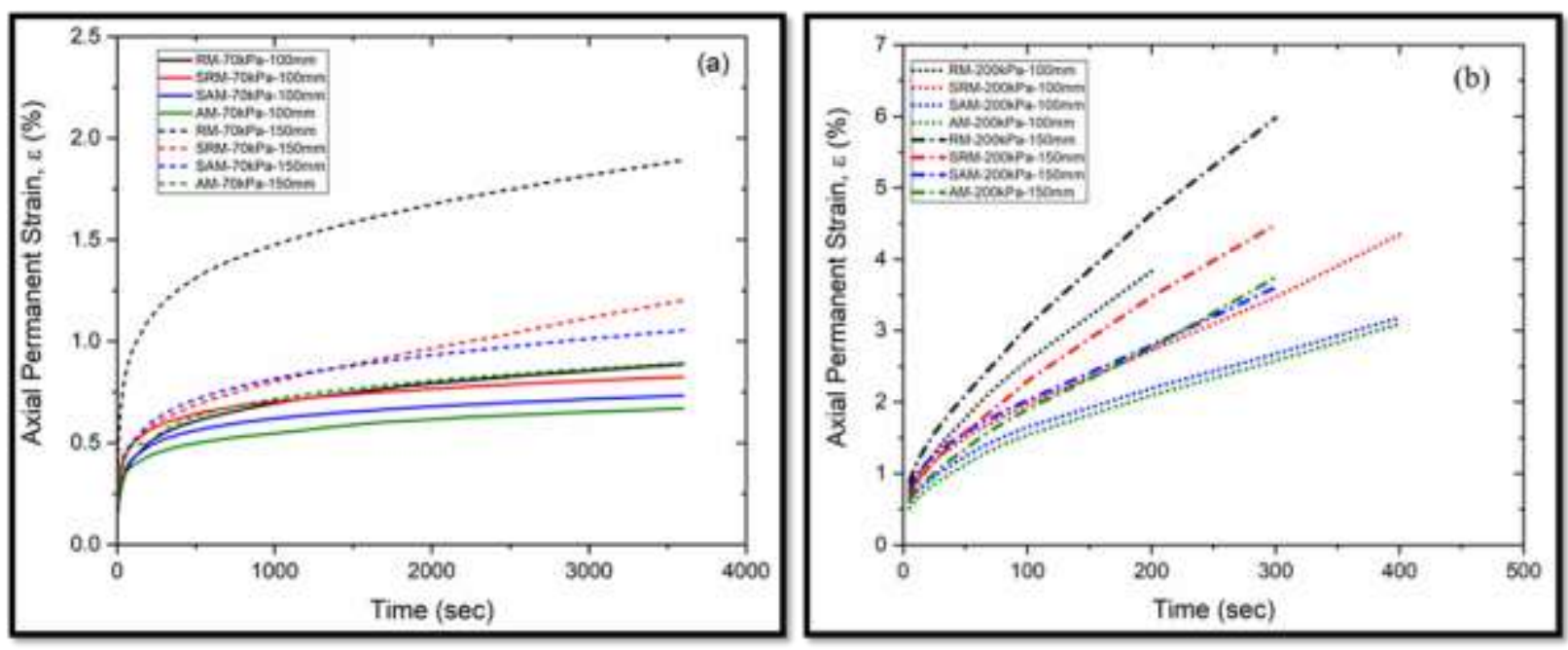

Figure 12: Asphalt Concrete RLAT creep behaviour at (a) $25^{\circ} \mathrm{C}$ (b) $40^{\circ} \mathrm{C}$ 

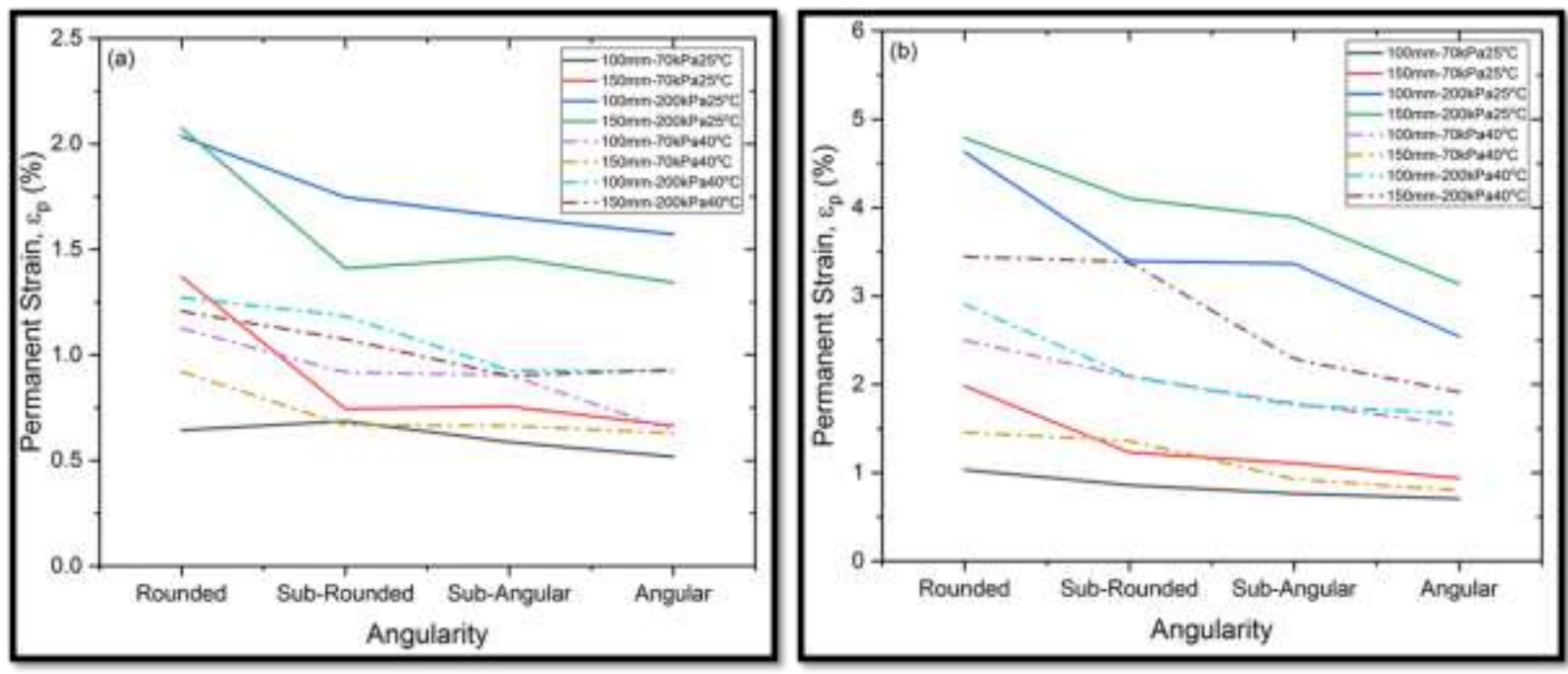

Figure 13: Deformation at start of transition zones (a) secondary (b) tertiary

An algorithm developed by [7] using a Newton-Raphson iterative numerical method, calculates and identifies the various zones of permanent deformation versus loading application. As shown in Fig. 9, there exists a relationship between sample type and the strains at the transition zones. As the angularity index of the mixes increases, there is a decrease in the permanent strains at the transition zones at any given temperature. As previously observed, the high strain values exist in taller samples, high temperatures and loading stresses. This behaviour has been theoretically accepted in the literature. The difference between strains at $200 \mathrm{kPa}$ loading and $25{ }^{\circ} \mathrm{C}$ are approximately $200 \%$ higher than that recorded at the lower stress levels. However, the values at $40{ }^{\circ} \mathrm{C}$ are nearly identical.

\section{Conclusions}

The stability of pavement mixtures increases with increased angularity of the coarse aggregate materials in flexible asphalt pavements. The aggregate imaging system (AIMS) which is not subjected to human error evaluated the angularity for each individual coarse aggregate particle index (CAI). This study to expanded on the entire classification of coarse angularity which informed of the significant distinction of the behaviour of mixes due to changes in angularity.

The stress-strain parameters (initial tangent modulus, strain at peak stress and compressive strength) derived from the research can be used as input parameters in pavement modelling programmes to model and simulate the behaviour (both elastic and plastic) of asphalt concrete, which is an integral part of the design and evaluation of pavement structures.

Static and repeated load tests are methodologies commonly used to evaluate the permanent deformation susceptibility of asphalt concrete mixtures in the laboratory. The samples sizes and test procedures provided an explanation of the linear relationship that exists between aggregate particle angularity and permanent strains. Static creep unrecovered strains is greater than that of repeated loading. Permanent deformation strain is not only affected by temperature or stress levels but also by the properties (angularity) of the aggregate which provides increased particle interlock. Increased aggregate interlock provides a decrease in the rutting distress of a HMA pavement. The 
sub-angular and angular mixes show a small difference in the results of permanent strain. This could indicate that an acceptable limit of angular aggregates can be adequate as a criterion for angularity limits.

The stability of pavement mixtures increases with increased angularity of the coarse aggregate materials in flexible asphalt pavements. Rounded aggregates provided minimal aggregate interlock, and as particles easily roll over one another allowing movement within the mix, and greater increase in deformation. Aggregate angularity has a significant relationship with the susceptibility of HMA to deformation. This is true for all cases of stress levels, sample heights and temperatures.

Current minimum criteria for aggregate angularity in HMA pavement mixtures influences mix designs, construction costs and asphalt performance. Hence, the enhancement of an aggregate angularity criterion is important for road and highway organisations.

The study focused on limestone and river gravel. Aggregates are known to be different in every region or country. Therefore, a recommendation for future work is to use the methodologies within this research to design and increase the data set to include common aggregate materials such as basalt, quartzite to name a few. The approach of using a different imaging system for the measurement of aggregate angularity to evaluate mixture performance is also recommended.

\section{References}

[1] Bessa, I.S., et al., 2014. Aggregate shape properties and their influence on the behavior of hotmix asphalt. Journal of Materials in Civil Engineering, 27 (7), 04014212.

[2] Brown, S. and Brunton, J., 1992. An introduction to the analytical design of bituminous pavements, University of Nottingham, Department of Civil Eng. Nottingham UK.

[3] Ghasemi, Parnian, Mohamad Aslani, Derrick K. Rollins, and R. C. Williams. 2018.Principal Component Analysis-Based Predictive Modeling and Optimization of Permanent Deformation in Asphalt Pavement: Elimination of Correlated Inputs and Extrapolation in Modeling. Structural and Multidisciplinary Optimization 59 (4):1335-1353. doi:10.1007/s00158-018-2133-x.

[4] Huang, B., et al., 2009. Effects of coarse aggregate angularity and asphalt binder on laboratory measured permanent deformation properties of HMA. International Journal of Pavement Engineering, 10 (1), 19-28.

[5] Kim, Y.R. and Souza, L.T., 2009. Effects of aggregate angularity on mix design characteristics and pavement performance.

[6] Kok, B. V., and Kuloglu, N. 2007. The effects of different binders on mechanical properties of hot mix asphalt. International Journal of Science \& Technology 2(1), 41-48.

[7] Leon, L. and Charles, R., 2015. Impact of coarse aggregate type and angularity on permanent deformation of asphalt concrete. Computational Methods and Experimental Measurements XVII, 59, 303-313.

[8] Little, D., et al., 2003. Quantify shape, angularity and surface texture of aggregates using image analysis and study their effect on performance. Rep. No. 0-1707, 4.

[9] Pan, T., Tutumluer, E., and Carpenter, S.H., 2006. Effect of coarse aggregate morphology on permanent deformation behavior of hot mix asphalt. Journal of transportation engineering, 132 (7), 580-589. 
[10] Pouranian, M. Reza, Reza Imaninasab, and Mehdi Shishehbor. 2018. The Effect of Temperature and Stress Level on The Rutting Performance of Modified Stone Matrix Asphalt. Road Materials and Pavement Design. doi: 10.1080/14680629.2018.1546221.

[11] Rismantojo, E., 2002. Permanent deformation and moisture susceptibility related aggregate tests for use in hot-mix asphalt pavements.

[12] Roy, Neethu, A. Veeraragavan, and J. Murali Krishnan. 2016. Influence of Confinement Pressure and Air Voids on the Repeated Creep and Recovery of Asphalt Concrete Mixtures. International Journal of Pavement Engineering 17 (2):133-147.

[13] Souza, L.T., et al., 2012. Experimental testing and finite-element modeling to evaluate the effects of aggregate angularity on bituminous mixture performance. Journal of Materials in Civil Engineering, 24 (3), 249-258.

[14] Wadell, H., 1932. Volume, shape, and roundness of rock particles. The Journal of Geology, 40 (5), 443-451. 